\title{
ENSO variability in the deuterium-excess record of a coastal Antarctic ice core from the McMurdo Dry Valleys, Victoria Land
}

\author{
N.G. PATTERSON, ${ }^{1,2}$ N.A.N. BERTLER, ${ }^{1}$ T.R. NAISH ${ }^{1,}{ }^{12}$ U. MORGENSTERN ${ }^{2}$ \\ ${ }^{1}$ Antarctic Research Centre, Victoria University of Wellington, PO Box 600, Wellington, New Zealand \\ E-mail: n.patterson@gns.cri.nz \\ ${ }^{2}$ Institute of Geological and Nuclear Sciences Ltd, PO Box 30368, Lower Hutt, New Zealand
}

\begin{abstract}
The El Niño-Southern Oscillation (ENSO) signal in coastal Antarctic precipitation is evaluated using deuterium-excess data measured from an ice core located at Victoria Lower Glacier (VLG) Dome, McMurdo Dry Valleys. Recent studies suggest that interannual variations in the intensity and position of the Amundsen Sea low, a low-pressure centre that controls moisture flux in the West Antarctic sector, is modulated by the ENSO. Deuterium-excess values from the VLG ice core, which serve as a proxy for changes in regional moisture flux, exhibit oscillations of equivalent duration to those observed in the Southern Oscillation Index (SOI). Results of cross-spectral analyses show that temporal fluctuations in deuterium excess and the SOI covary and are coherent at $\sim 4.9,3.6,3.0,2.6,2.4$ and 2.0 year frequencies between 1950 and 2000. We ascribe this covariance to shifts in the source and transport pathway of precipitation that is deposited in coastal Victoria Land as a consequence of ENSO's influence. High values of deuterium excess are consistent with increased meridional flow carrying warm, moist air southward across the Ross Sea when the low-pressure centre is positioned to the north of the Ross Ice Shelf (La Niña mode). Low deuterium-excess values, which reflect a more westerly to southerly flow across the West Antarctic ice sheet and Ross Ice Shelf leading to cooler and drier en-route conditions, occur when the low-pressure centre is positioned above the Amundsen Sea (El Niño mode).
\end{abstract}

\section{INTRODUCTION}

The relationship between deuterium-excess variations in glacier ice and atmospheric circulation provides an important tool for deciphering the climate record held in ice cores. A number of studies have utilized the isotopic composition of glacier ice as a proxy for tracing variations in regional moisture flux, specifically the origin and transport pathway of precipitation (Kato, 1978; Bromwich and Weaver, 1983; Ichiyanagi and others, 2002; Vimeux and others, 2002). Hydrogen and oxygen isotopic ratios in precipitation are the products of a succession of fractionation processes that occur at each phase change of water during its evaporation, transportation and deposition (Dansgaard, 1964). Under non-equilibrium conditions, kinetic effects disturb the coeval fractionation of hydrogen and oxygen isotopes (Epstein, 1956). Differential fractionation of water isotopes is typically measured by the deuterium-excess parameter $\mathrm{d}=\delta \mathrm{D}-8 \delta^{18} \mathrm{O}$, where $\delta \mathrm{D}$ and $\delta^{18} \mathrm{O}$ represent ${ }^{2} \mathrm{H} /{ }^{1} \mathrm{H}$ and ${ }^{18} \mathrm{O} /{ }^{16} \mathrm{O}$ respectively (Dansgaard, 1964). On interannual to decadal timescales, deuterium-excess variations are considered to reflect changes in distance from the primary moisture source (Vimeux and others, 2002) and precipitation transport pathways (Ichiyanagi and others 2002), and thus may be used to reconstruct palaeocirculation patterns and the past behaviour of climate oscillators and/or dipoles such as the El Niño-Southern Oscillation (ENSO).

In the Antarctic, the ENSO is recognized as an important driver of atmospheric and oceanic circulation variability at interannual to decadal timescales (Ribera and Mann, 2003; Turner, 2004). Instrumental measurements and ice-core data indicate linkages between the tropical Pacific Ocean ENSO and Antarctic climate phenomenon, most probably via signal propagation along the South Pacific Convergence Zone (Turner, 2004). Positive (La Niña) and negative
(El Niño) pressure and temperature anomalies have been observed to fluctuate with the Southern Oscillation index (SOI), with a lag of approximately 1 year (Savage and others, 1988; Smith and Stearns, 1993; Turner, 2004). There are now a number of studies that have identified variations in Antarctic atmospheric temperature (e.g. Savage and others, 1988; Smith and Stearns, 1993), pressure (e.g. Smith and Stearns, 1993), sea-ice extent (e.g. Gloersen, 1995) and the chemical (e.g. Kreutz and others, 2000; Meyerson and others, 2002) and isotopic (e.g. Ichiyanagi and others, 2002) composition of precipitation at ENSO frequencies, i.e. cycles of 2-7 years. A continent-wide study of atmospheric pressure and temperature variations found that the largest anomalies were recorded at Scott Base (Smith and Stearns, 1993), suggesting that ENSO-driven climate variability may be amplified in the McMurdo Sound area.

ENSO-controlled climate variability in the Ross and Amundsen Seas has been linked to interannual changes in terrestrial atmospheric temperature and precipitation patterns in the McMurdo Dry Valleys (Bertler and others, 2004a). During La Niña events, the Amundsen Sea low (ASL), a dominant, semi-stable pressure anomaly, is located to the north of the Ross Sea (Cullather and others, 1996; Bromwich and others, 2000), resulting in relatively warm, moist air being transported to the Victoria Land coast (Bertler and others, 2004a; Fig. 1). During some El Niño events, the ASL deepens and migrates westward by as much as $1400 \mathrm{~km}$, promoting enhanced air-mass transport across West Antarctica and leading to warmer temperatures and higher precipitation rates in Marie Byrd Land (Bromwich and others, 2000; Fig. 1). The enhanced cyclonic activity in the Amundsen Sea has been shown to lead to air-mass ascent over the West Antarctic ice sheet (WAIS) and intensified katabatic winds across the western Ross Ice Shelf including the McMurdo Dry Valleys (Bromwich and others, 
2000). As a result, the transport pathway of precipitation deposited in the McMurdo Dry Valleys is characterized by cooler temperature and lower relative humidity during El Niño events than during La Niña events (Bertler and others, 2004a).

In this study, we make a contribution towards understanding the role of the ENSO in modulating Antarctic climate variability, by evaluating the relationship between the SOI and the deuterium-excess record of a new coastal Antarctic ice core from Victoria Lower Glacier (VLG) McMurdo Dry Valleys. We explore the use of deuteriumexcess data as a proxy for variations in temperature and humidity during moisture transportation as a consequence of ENSO-influenced migrations in the precipitation source and transport pathways of moisture deposited in coastal Victoria Land.

\section{ICE-CORE SITE}

Mass-balance measurements at VLG since 1983 (Chinn, 1998) and annual measurements since 1999 (Bertler, 2003) indicate that the glacier has net accumulation. In order to assess the structure and flow dynamics of VLG, groundpenetrating radar (GPR) surveying was undertaken in the austral summer of 2000/01 (Bertler, 2003). GPR imaging showed consistent horizontal layering, which is interpreted as indicating a lack of major flow disturbances, in the upper $\sim 50 \mathrm{~m}$ of the glacier (Bertler, 2003). The ice-bedrock contact appeared as a sinuous reflector, indicating a maximum glacier thickness of $300 \pm 20 \mathrm{~m}$ (Bertler, 2003). Consequently, VLG Dome, located above the trough centre at $77^{\circ} 19^{\prime} 48^{\prime \prime} \mathrm{S}, 162^{\circ} 31^{\prime} 55^{\prime \prime} \mathrm{E}$, was chosen as the VLG icecore site (Fig. 2).

The VLG ice core was acquired in the early austral summer of 2001/02. Drilling took place at $626 \mathrm{~m}$ a.s.I. and $22.5 \mathrm{~km}$ inland from the McMurdo Sound coast, western Ross Sea. A total of $182.4 \mathrm{~m}$ of ice core was extracted from

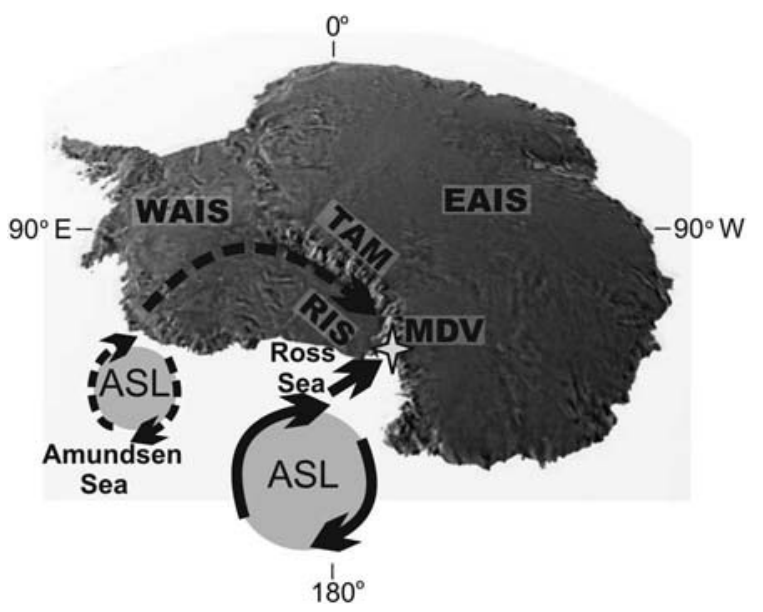

Fig. 1. ENSO-controlled migration of the ASL (modified from Meyerson and others, 2002; Bertler and others, 2004a). Note that the size of the ASL depicts its strength, and the arrows indicate typical wind trajectory paths. During La Niña events (solid arrows) the ASL is located to the north of the Ross Ice Shelf, resulting in moisture transport above the relatively warm, humid Ross Sea prior to precipitation in the McMurdo Dry Valleys (MDV). During some El Niño events (dashed arrows) the ASL is located to the north of Marie Byrd Land above the Amundsen Sea. As a result, moisture is transported over the relatively cold, dry West Antarctic ice sheet (WAIS) and Ross Ice Shelf (RIS) before being precipitated in the MDV. Katabatic winds flow eastward across the Transantarctic Mountains (TAM), preventing moisture flux from the West Antarctic sector penetrating the East Antarctic ice sheet (EAIS). The background, i.e. Antarctic continent, is a NASA Goddard RADARSAT satellite image (1997).

the ice divide of the glacier, of which the upper $5.7 \mathrm{~m}$ comprises the dataset on which this study is based. The dataset represents the time period 1950-2000, as the uppermost $11 \mathrm{~cm}$ of the core was lost during drilling.

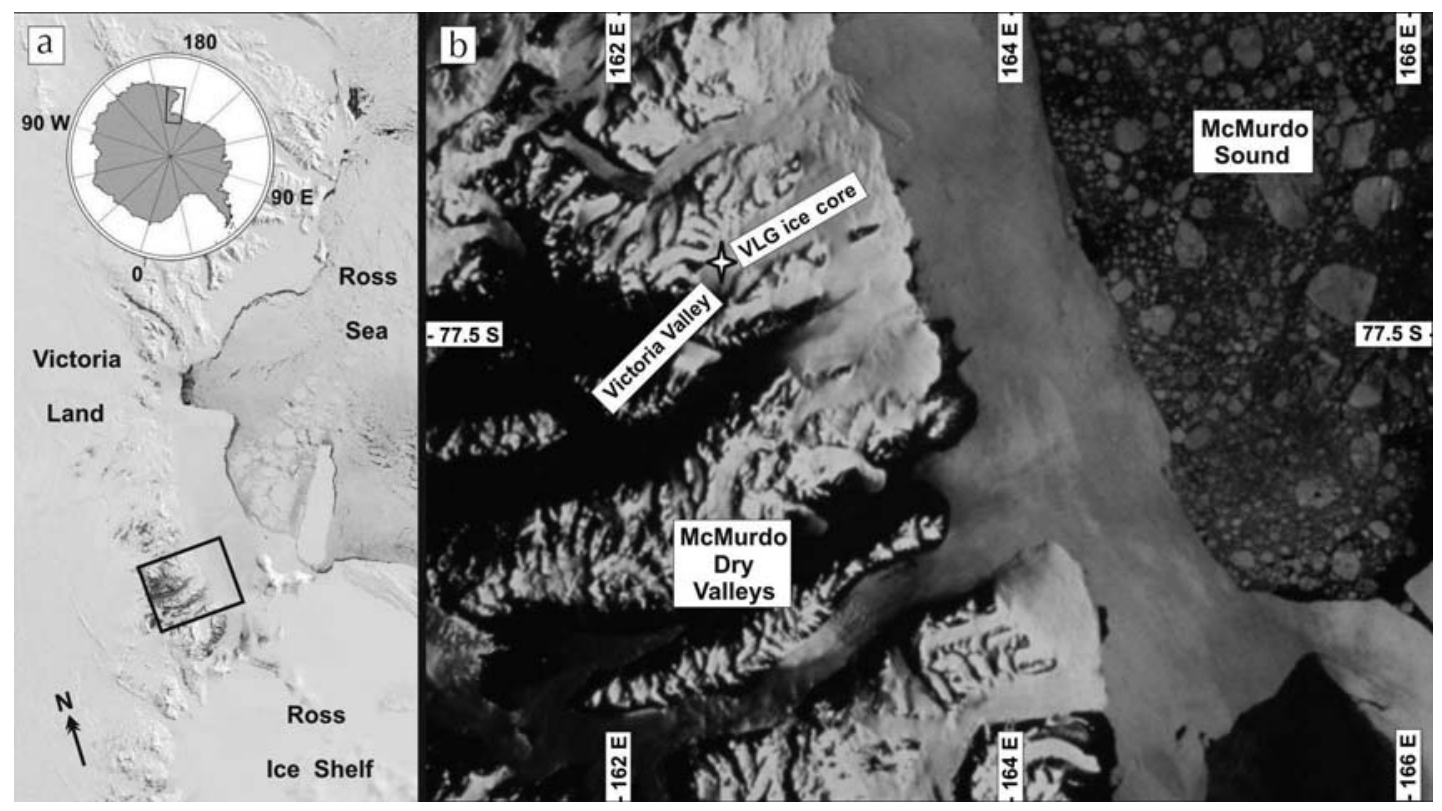

Fig. 2. Location map. (a) Victoria Land and the western Ross Sea. The black rectangle encompasses the McMurdo Sound area, which is shown in greater detail in (b). The background is a NASA Goddard Space Flight Center satellite image (2001) from the moderate-resolution imaging spectroradiometer (MODIS) sensor of the Terra satellite (J. Descloitres, MODIS Land Rapid Response Team). (b) McMurdo Sound area. The VLG ice-core site is depicted by a white star. The background is a Landsat (1973) satellite image. 
a VLG-core age tie points and tritium benchmarks

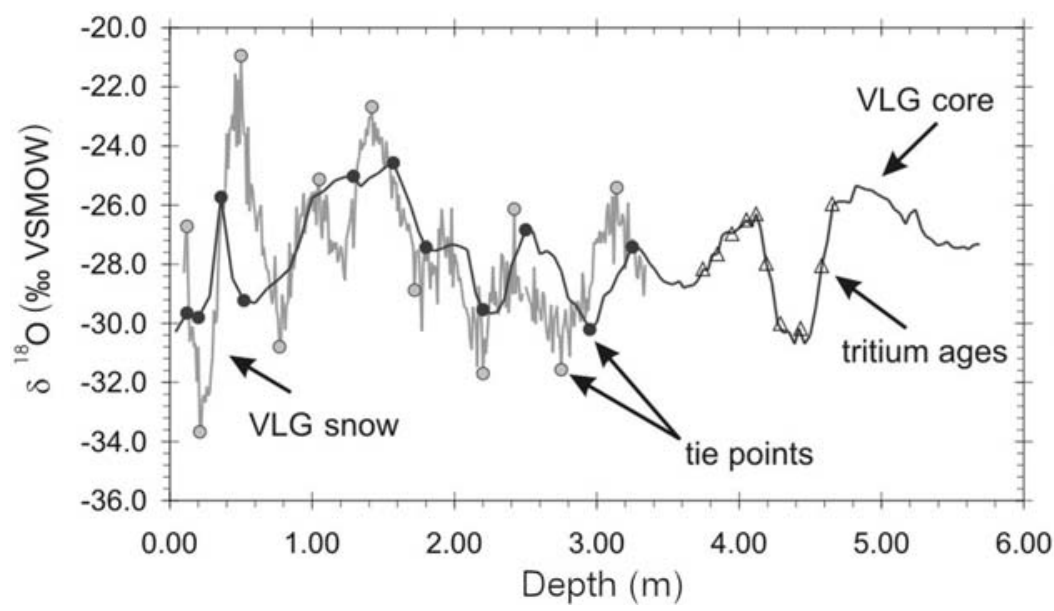

b VLG-core age model

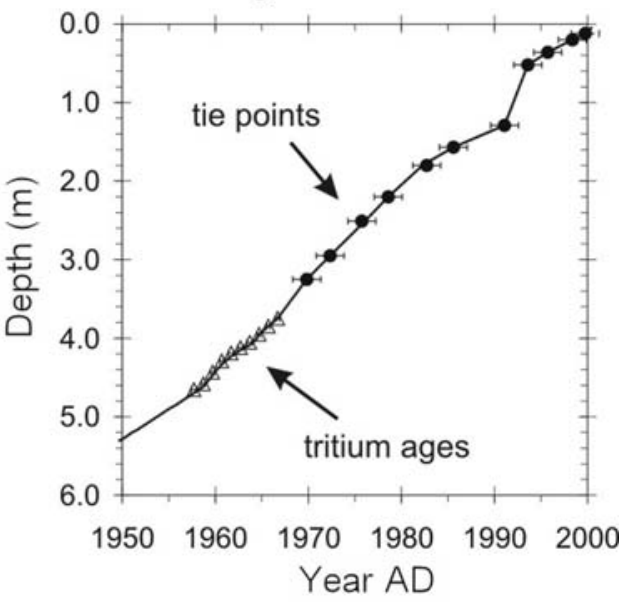

Fig. 3. (a) Age tie points and tritium ages used to date the VLG ice core. The VLG ice-core data (black line) were tuned to annually dated snow-pit data (grey line). The snow-pit data (VLG snow) were dated using seasonal variations in the chemistry record and have an age uncertainty of \pm 1 year (Bertler and others, 2004b). In total, 11 identified tie points were used to tune the VLG ice-core record (black solid circles) to the well-dated VLG snow record (grey solid circles). The age uncertainty of the VLG core in this section is \pm 1.5 years due to the coarser sampling resolution of the VLG core. Beyond the reach of the VLG snow data, 144 high-resolution tritium measurements were used to depict the onset of the nuclear testing and seasonal tritium variations between 1957 and 1966 (open triangles). The associated error lies between \pm 0.2 and 0.3 years. In total, 23 independent ages were used to date the VLG core record. (b) Linear interpolation and a firn decompaction model were used to interpolate between and extrapolate beyond age benchmarks, respectively. Error bars indicate the \pm 1.5 years age uncertainty of the oxygen isotope tie points. The error bars of the tritium age uncertainty ( $\pm 0.2-0.3$ years) are smaller than the symbol and are therefore not shown.

\section{CHRONOLOGY}

The record was temporally constrained using tie points from well-dated snow-pit data and independent tritium measurements. During November 2000 a $3.25 \mathrm{~m}$ snow pit was sampled with $1 \mathrm{~cm}$ resolution $2 \mathrm{~km}$ south of the VLG drill site. The oxygen isotope record of the snow pit was dated with \pm 1 year age uncertainty using seasonal snow chemistry variation (Bertler and others, 2004b). The obtained depthage conversion was then applied to the oxygen data measured on aliquots of the chemistry samples. Good agreement between the oxygen data and the $100 \mathrm{~km}$ distant Scott Base temperatures, in particular summer temperatures, provided independent verification of the age model (Bertler and others, 2004a). In contrast, the sampling resolution of the VLG core data is too coarse $(>3 \mathrm{~cm})$ to allow identification of seasonal chemistry variations. Instead, we compare the oxygen ratios of the core with those of the nearby snow-pit data (Fig. 3a). The reported depth of the VLG core is relative to the new surface $(-11 \mathrm{~cm})$. Overall, 11 tie points (Fig. 3a and b, grey and black circles) were identified to $3.25 \mathrm{~m}$ depth (=AD 1970). While the snow-pit data are characterized by a larger range of high frequencies, interannual variability is apparent in both records, providing reasonable age control. However, due to the sampling resolution of the VLG core record $\left(\sim 1-3\right.$ samples $\left.^{-1}\right)$ the age uncertainty increases to \pm 1.5 years.

Below $3.25 \mathrm{~m}$ depth, high-resolution tritium measurements (Fig. 3a and b, open triangles) were used to identify the arrival of bomb tritium during the atmospheric nuclear weapons testing period (Pourchet and Pinglot, 1979). During Antarctic winters the absence of the tropopause promotes this bomb tritium to transfer from the stratosphere to the troposphere, with pronounced peaks preserved in winter snow, albeit with a 2 year time lag (Taylor, 1971). For tritium determination in the upper VLG ice core, vacuum distillation was used to separate tritium from other beta fallout components in the ice samples, and tritium concentrations were measured using ultra-low-level liquid scintillation spectrometry (QuantulusTM) without enrichment (Morgenstern, in press). In total, 144 tritium samples were measured, identifying ten characteristic seasonal tritium peaks between 1957 and 1967 with $\pm 0.2-0.3$ years age uncertainty. Between 1967 and 2000, identification of seasonal tritium variability is less certain due to coarser sample resolution in the low-density material in the upper section of the core, and less pronounced seasonal peaks in the tritium precipitation.

Overall, 23 independent ages were used to date the VLG core record (Fig. 3b). Linear interpolation and a firn decompaction model were employed to interpolate between and extrapolate beyond age benchmarks, respectively.

\section{METHODS}

\section{Isotope measurements}

VLG ice-core samples spanned 3.4-8.0 cm depth intervals yielding one to three isotopic measurements per year for the 1950-2000 period. Oxygen isotope ratios $\left(\delta^{18} \mathrm{O}\right)$ were measured using a Europa Geo 20-20 mass spectrometer, while hydrogen isotope ratios $(\delta \mathrm{D})$ were measured using a VG Micromass 602 mass spectrometer. The $\delta^{18} \mathrm{O}$ and $\delta \mathrm{D}$ measurements are associated with standard errors of $\pm 1.9 \%$ and $\pm 0.19 \%$, respectively. Consequently, a maximum standard deviation of $\pm 2.25 \%$ is associated with the deuterium-excess data. This is an upper limit for the standard deviation because $\delta^{18} \mathrm{O}$ and $\delta \mathrm{D}$ are known to be dependent.

\section{Spectral analyses}

We use the Spectrum program (Schulz and Stattegger, 1997), which is based on the Lomb-Scargle Fourier transform 
a Unfiltered SOI (dashed) and deuterium-excess (solid) time series

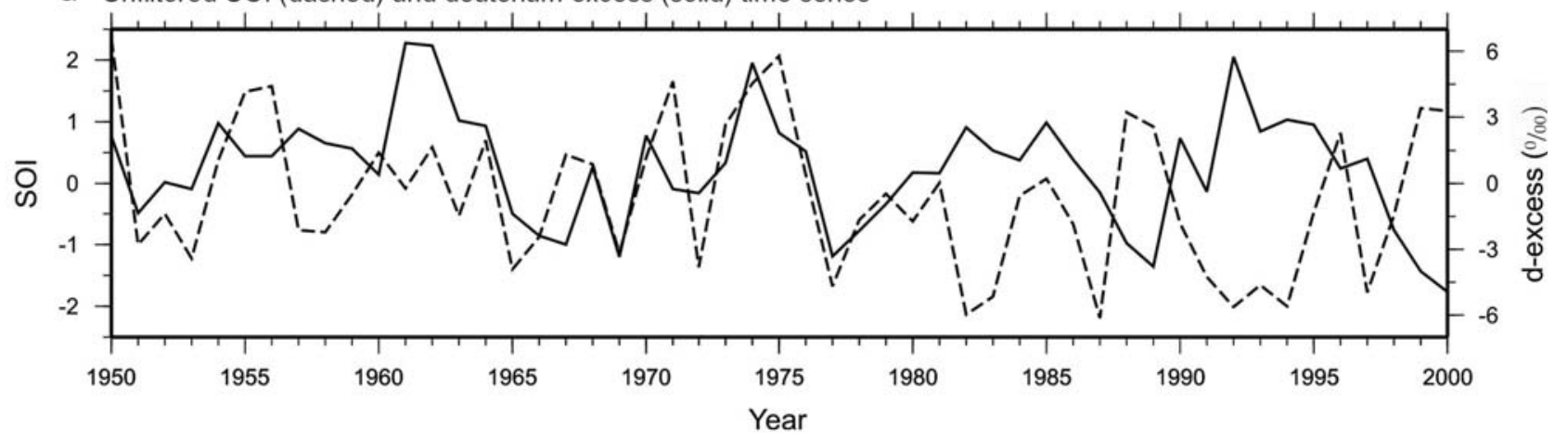

b SOI harmonics (unfiltered)

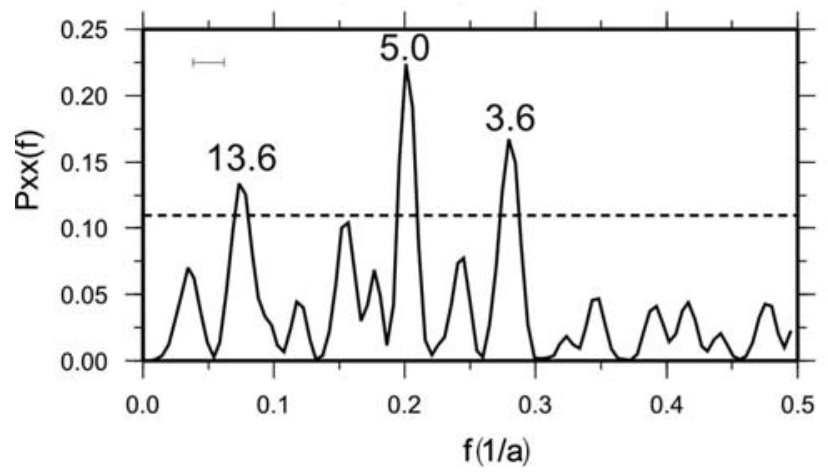

C Deuterium-excess harmonics (unfiltered)

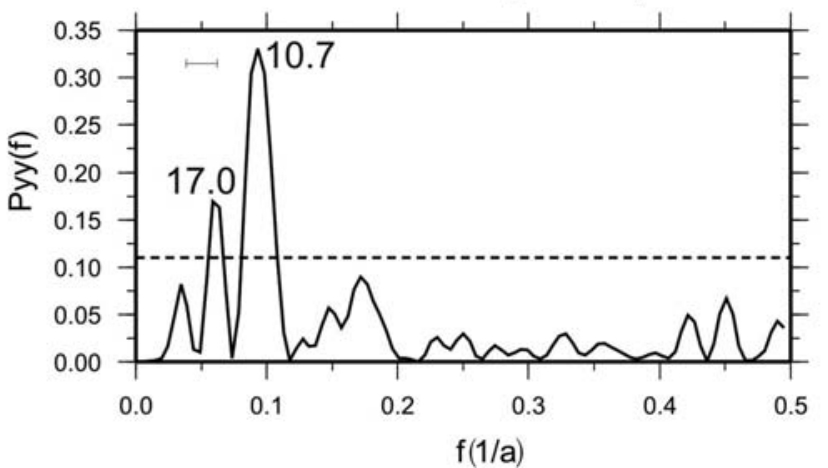

Fig. 4. (a) Raw 1950-2000 time series for SOI (http://www.cgd.ucar.edu/cas/catalog/climind/soi.html) and deuterium excess (1950-2000) as recorded in the VLG ice core. (b, c) Spectrum 2.1 (Schulz and Stattegger, 1997) harmonic analyses run with the following settings: oversampling factor $(\mathrm{OFAC})=4$, highest frequency factor $(\mathrm{HIFAC})=1$, level of significance $=0.01$ and $\lambda=0.4$, i.e. Siegel's (1980) test for three to four periodic components. Note that the horizontal bars mark $6 \mathrm{~dB}$ bandwidth uncertainties, and the numbers above the peaks denote respective periods.

(Lomb, 1976; Scargle, 1982, 1989) for unevenly spaced time series, in combination with a Welch-overlapped-segmentaveraging procedure (Welch, 1967; Percival and Walden, 1993) for spectral estimates. The occurrence of ENSO frequencies within the deuterium-excess data is explored by a cross-spectral analysis with a 50 year time series of $\mathrm{SOI}$ data (calculated from the twice-normalized difference between the sea-level pressures at Tahiti and Darwin (Parker, 1983)) (Fig. 4a).

Visual and harmonic inspections of the unfiltered VLG deuterium-excess time-series data show two and a half $\sim 20$ year cycles, and five 210 year cycles, onto which interannual cycles of 2-7 years duration are superimposed (Fig. $4 \mathrm{~b}$ and $\mathrm{c}$ ). As the deuterium-excess time series only represents 50 years, the low-frequency, inter-decadal cycles are not assessed here by spectral analysis and are the focus of ongoing work. Nonetheless, we note that they are of similar duration to the 11 year solar forcing cycle. Here, however, we address the nature of the sub-decadal, interannual variability by undertaking spectral analysis of filtered SOI and deuterium-excess data in the frequency domain.

Interannual oscillations in the raw SOI and deuteriumexcess time series (Fig. 4a) were amplified by applying a 10 year low-pass Gaussian filter to these data (Fig. 5a). As a result, spectral power was concentrated in the ENSO frequency bands, and low-frequency peaks lacking statistical significance were muted. A harmonic analysis, which utilizes Siegel's (1980) test for the identification of up to three periodic components within a normalized periodogram, was applied to the filtered time series in order to detect quasi-periodic components in the presence of noise (Fig. 5b and c). Cross-spectral analysis of the SOI deuterium-excess time series was undertaken to evaluate the coherency in signal amplitude and frequency between the ENSO forcing function (SOI) and the precipitation source/pathway proxy data (deuterium excess) (Fig. 5d-g). For this the filtered deuterium-excess data were interpolated at annual intervals to match the time-step of the yearly SOI data.

\section{RESULTS}

Harmonic spectral analysis of the filtered SOI data (Fig. 5a) shows periodic signal above noise levels concentrated in the known ENSO frequency bands of 6.6, 5.0 and 3.6years (Fig. 5b; 99\% significance level). Harmonic analysis of the filtered deuterium-excess data (Fig. 5a) confirms the observed (visual) low-frequency cyclicity and identifies periodic components above background noise levels in a $\sim 6.0$ year frequency band (Fig. 5c; 99\% significance level). Both time series covary (Fig. 5f; 95\% significance level) and are coherent (Fig. 5g; 99\% significance level) at 4.9, 3.6, $3.0,2.4$ and 2.2 years, suggesting a forcing relationship between ENSO and deuterium-excess variations in the VLG ice core. The 6 year deuterium-excess peak (Fig. 5c and e), while within $6 \mathrm{~dB}$ bandwidth and cross-correlated with the 6.6 year SOI peak (Fig. 5b, d and f), is not statistically coherent between the two time series on the $95 \%$ significance level (Fig. 5g). 
a Filtered SOI (dashed) and deuterium-excess (solid) time series

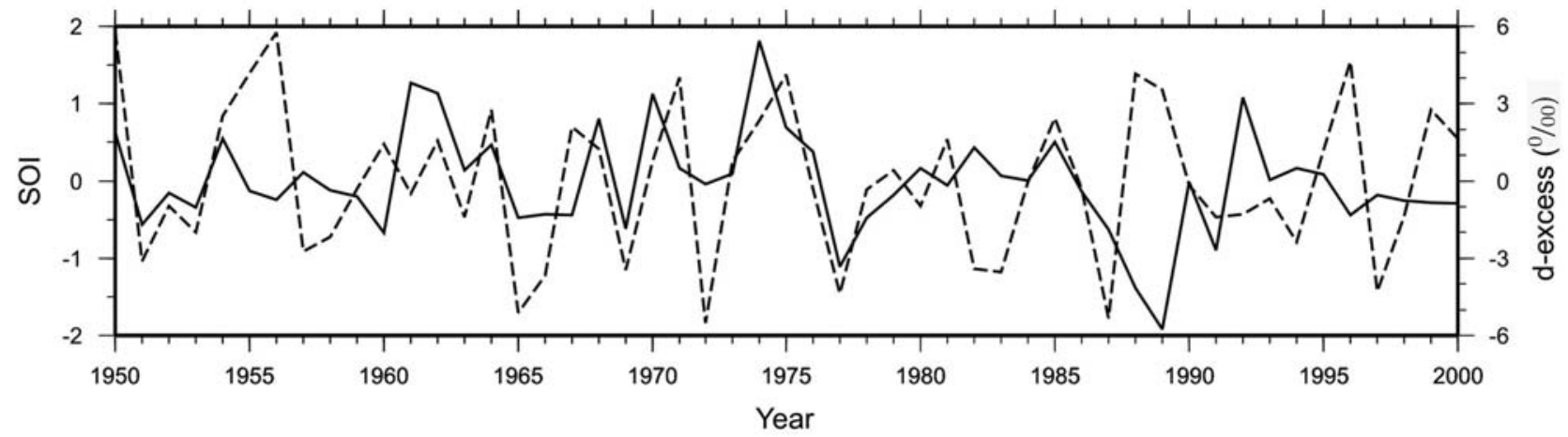

b sOI harmonics (filtered)

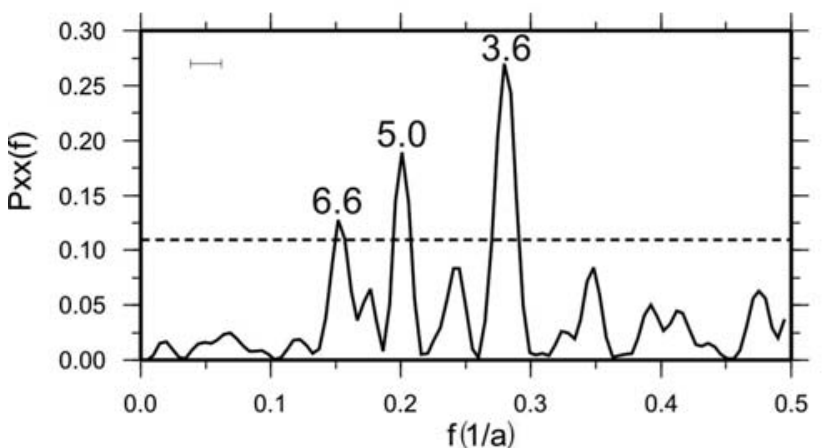

d SOI autospectrum (filtered)

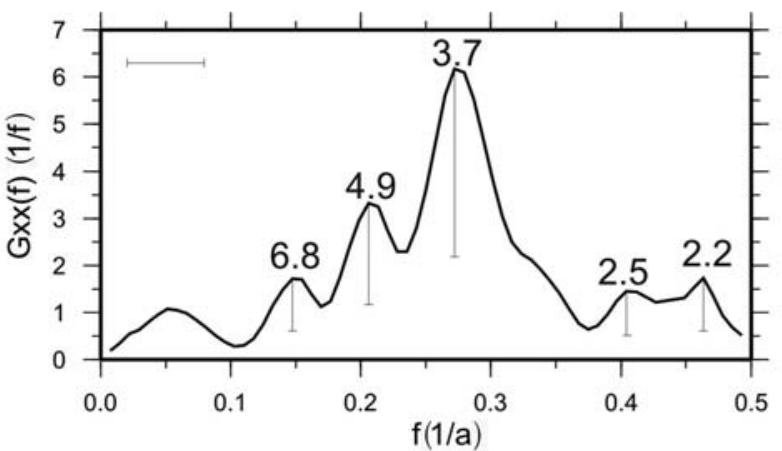

f SOI-d-excess cross-correlation

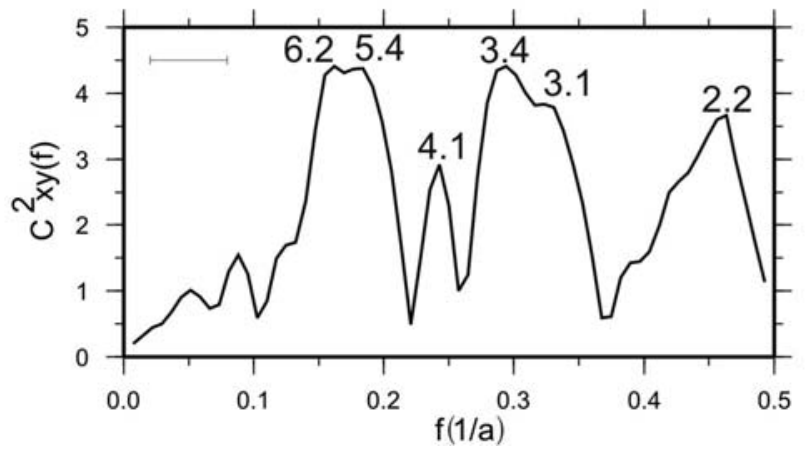

C Deuterium-excess harmonics (filtered)

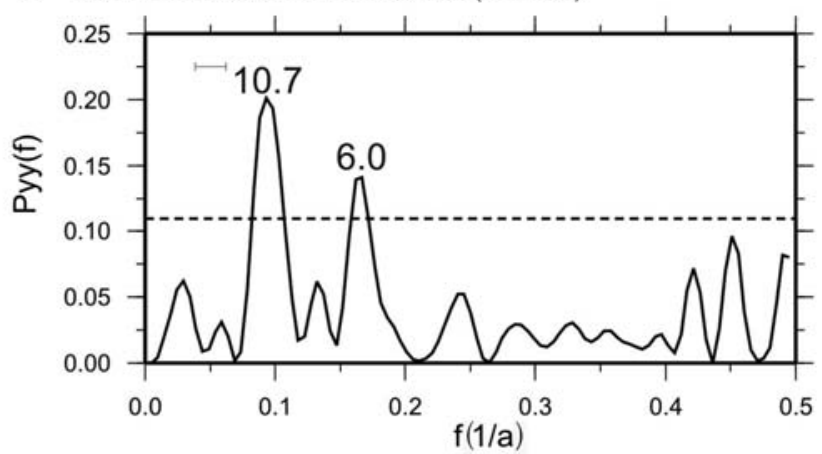

e Deuterium-excess autospectrum (filtered)

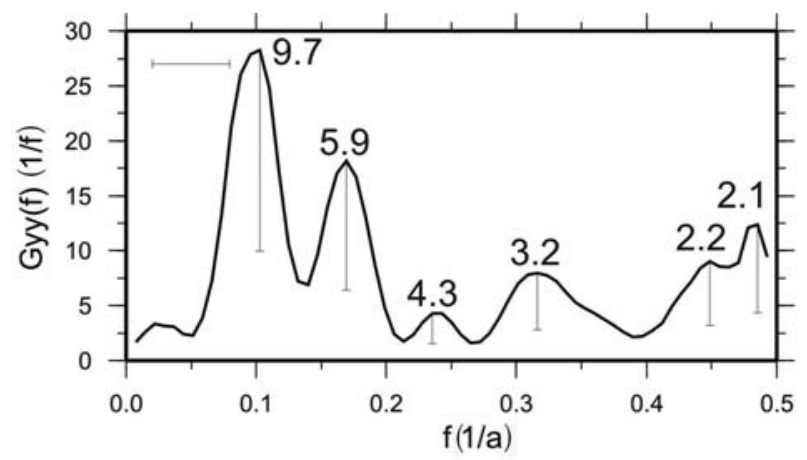

g SOI-d-excess coherency

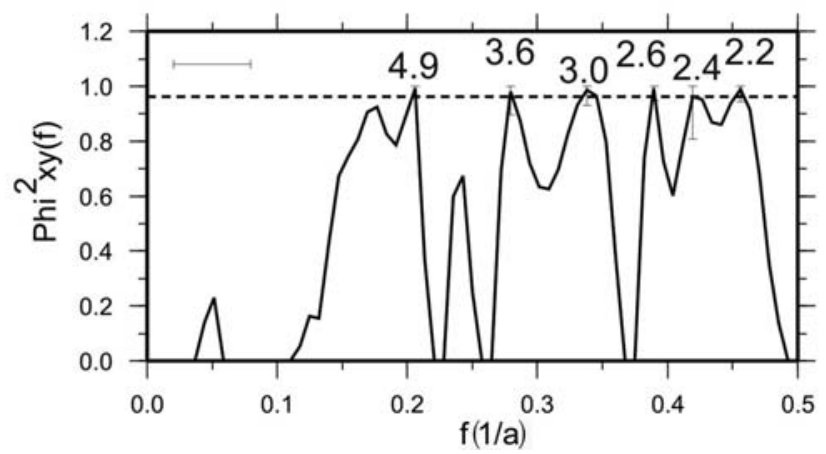

Fig. 5. (a) Cross-spectral analyses of filtered 1950-2000 time series (10 year low-pass Gaussian filter) for SOI (http://www.cgd.ucar.edu/cas/ catalog/climind/soi.html) and deuterium excess as recorded in the VLG ice core. Spectral analyses were run using harmonic and bivariate modules of Spectrum 2.1 (Schulz and Stattegger, 1997). (b, c) Harmonic analyses of SOI data (b) and deuterium-excess data (c), employing Siegel's (1980) noise test, run with the following settings: OFAC $=4, \mathrm{HIFAC}=1$, level of significance $=0.01$ and $\lambda=0.4$, i.e. Siegel's test for three to four periodic components. Note that the horizontal bar marks $6 \mathrm{~dB}$ bandwidth uncertainties, and the numbers above the peaks denote respective periods. ( $\mathrm{d}-\mathrm{g}$ ) Autospectrum of filtered SOI data (d), autospectrum of filtered deuterium-excess data (e), crosscorrelation $(\mathrm{f})$ and coherency of the filtered SOI and deuterium-excess data (g), run with the following settings: OFAC $=4$, HIFAC $=1$, number of segments $=2$, Hanning window and level of significance $=0.05$. The dashed line on the coherency plot indicates false-alarm level (0.962). The time series are coherent at the $\sim 4.9,3.6,3.0,2.6,2.4$ and 2.0 year ENSO frequencies. 


\section{DISCUSSION}

The identification of significantly coherent $\sim 4.9,3.6,3.0$, 2.6, 2.4 and 2.2 year cycles in SOI and VLG deuteriumexcess data over the last 50 years may suggest that the ENSO influences isotopic fractionation in coastal Victoria Land precipitation. We suggest that covariance and coherency in the SOI and VLG deuterium-excess time series can be attributed to temperature and humidity contrasts between two distinct atmospheric moisture-transport pathways, which are modulated by the ENSO. Here we elaborate on the nature of this linkage and present an argument for the ENSO modulating deuterium excess in coastal Victoria Land precipitation.

While oxygen and deuterium isotope ratios at high latitudes are predominantly an indicator of ambient air temperature at the time of precipitation, deuterium excess reflects non-equilibrium (kinetic) fractionation of stable water isotopes. These kinetic processes are controlled by atmospheric temperature and humidity in the source region, evaporation and precipitation during moisture transport, and air-mass mixing (Merlivat and Jouzel, 1979; Johnsen and others, 1989). For this reason, the geographical distribution of deuterium-excess values is used to calibrate atmospheric circulation models (Jouzel and others, 1991, 1994; Ciais and others, 1995; Hoffmann and others, 2000).

In the West Antarctic sector of the Southern Ocean, cyclonic activity is responsible for supplying $\sim 40 \%$ of the moisture flux to the Antarctic continent (Bromwich, 1990). Compilations of mean Antarctic cyclone tracks indicate that within the Southern Ocean the Ross and Amundsen Seas are probable moisture sources for cyclone-transported precipitation deposited within Victoria Land (Rockey and Braten, 1995; Simmonds and Keay, 2000; Carrasco and others, 2003). In the vicinity of the Ross and Amundsen Seas, the ASL is a principal semi-stable pressure anomaly promoting cyclonic activity (Cullather and others, 1996). The ASL exhibits migratory behaviour that is in phase with the ENSO (Cullather and others, 1996; Bromwich and others, 2000; Bertler and others, 2004a). During La Niña events, the ASL is located to the north of the Ross Ice Shelf, while during some El Niño events it is positioned off the coast of Marie Byrd Land (Cullather and others, 1996; Bromwich and others, 2000).

Cyclone trajectory paths show that moisture originating from these localities will travel along very different transport pathways prior to deposition in the McMurdo Sound area (Rockey and Braten, 1995; Simmonds and Keay, 2000; Carrasco and others, 2003). Moisture that is evaporated from the Southern Ocean to the north of the Ross Ice Shelf will travel above the relatively warm, humid Ross Sea before being precipitated in the McMurdo Dry Valleys (Bertler and others, 2004a). In contrast, moisture originating in the Amundsen Sea will ascend the relatively cold, dry WAIS before being deposited in the McMurdo Dry Valleys (Bertler and others, 2004a).

We contend that the two markedly different transport pathways during El Niño and La Niña modes of the ASL promote variations in the deuterium excess of snow precipitated within the Dry Valleys and coastal Victoria Land such that precipitation during El Niño events is associated with lower deuterium-excess values than precipitation during La Niña events. During El Niño events (Fig. 1) the Dry Valleys experience enhanced westerly to southerly flow across the WAIS and Ross Ice Shelf, leading to cooler, drier en-route conditions, causing lower deuterium-excess values. During La Niña events, the Dry Valleys precipitation is derived via increased meridional flow, carrying warm, moist air southward across the Ross Sea when the lowpressure centre is positioned to the north of the Ross Ice Shelf, leading to higher deuterium-excess values.

\section{CONCLUSIONS}

Significant oscillations of $\sim 4.9,3.6,3.0,2.6,2.4$ and 2.0 years are present in filtered VLG deuterium excess and SOl 1950-2000 time series. We attribute this common cyclicity to variations in atmospheric temperature and humidity during moisture transport promoting isotopic fractionation under non-equilibrium conditions and, consequently, variations in the deuterium-excess content of precipitation. Furthermore, we associate these climatic fluctuations with ENSO-influenced migrations of the source and transport pathways of precipitation that is deposited within the McMurdo Dry Valleys and coastal Victoria Land. Our results support the utility of deuterium excess as a tracer of interannual synoptic-scale climate variations that involve the modulation of the source and transport pathway of atmospheric moisture.

\section{ACKNOWLEDGEMENTS}

We thank A. Pyne and T. Kingan for logistical and technical support. Special thanks to K. Rodgers for assistance with isotopic measurements. We thank an anonymous reviewer for constructive and helpful comments on the manuscript. We are grateful for the support of Ice Coring and Drilling Services, Antarctica New Zealand, Scott Base and the US Antarctic Program. This research was supported by Foundation for Research Science and Technology Non-Specific Output Funding (FRST, NSOF) to G.N.S. and FRST funding (contract No. VICX0203) to V.U.W.

\section{REFERENCES}

Bertler, N.A.N. 2003. Understanding the climate behaviour of the McMurdo Dry Valleys, Antarctica, from coastal ice cores. (PhD thesis, Victoria University of Wellington.)

Bertler, N.A.N., P.J. Barrett, P.A. Mayewski, R.L. Fogt, K.J. Kreutz and J. Shulmeister. 2004a. El Niño suppresses Antarctic warming. Geophys. Res. Lett., 31(15), L15207. (10.1029/ 2004GL020749.)

Bertler, N.A.N., P.A. Mayewski, P.J. Barrett, S.B. Sneed, M.J. Handley and K.J. Kreutz. 2004b. Monsoonal circulation of the McMurdo Dry Valleys: signal from the snow chemistry. Ann. Glaciol., 39, 139-145.

Bromwich, D.H. 1990. Estimates of Antarctic precipitation. Nature, 343(6259), 627-629.

Bromwich, D.H. and C.J. Weaver. 1983. Latitudinal displacement from the main moisture source controls $\delta^{18} \mathrm{O}$ of snow in coastal Antarctica. Nature, 301(5896), 145-147.

Bromwich, D.H., A.N. Rogers, P. Kallberg, R.I. Cullather, J.W.C. White and K.J. Kreutz. 2000. ECMWF analyses and reanalyses depiction of ENSO signal in Antarctic precipitation. J. Climate, 13(8), 1406-1420.

Carrasco, J., D.H. Bromwich and A.J. Monaghan. 2003. Distribution and characteristics of mesoscale cyclones in the Antarctic: Ross Sea eastward to the Weddell Sea. Mon. Weather Rev., 131(2), 289-301.

Chinn, T.J. 1998. Recent fluctuations of the Dry Valleys glaciers, McMurdo Sound, Antarctica. Ann. Glaciol., 27, 119-124. 
Ciais, P., J.W.C. White, J. Jouzel and J.R. Petit. 1995. The origin of present-day Antarctic precipitation from surface snow deuterium excess data. J. Geophys. Res., 100(D9), 18,917-18,927.

Cullather, R.I., D.H. Bromwich and M.L. van Woert. 1996. Interannual variations in Antarctic precipitation related to El-NiñoSouthern Oscillation. J. Geophys. Res., 101(D14), 19,109$19,118$.

Dansgaard, W. 1964. Stable isotopes in precipitation. Tellus, 16(4), 436-468.

Epstein, S. 1956. Variations of the $\mathrm{O}^{18} / \mathrm{O}^{16}$ ratios of fresh water and ice. Nat. Acad. Sci., Nucl. Sci. Ser., 19, 20-25.

Gloersen, P. 1995. Modulation of hemispheric sea-ice cover by ENSO events. Nature, 373(6514), 503-506.

Hoffmann, G., J. Jouzel and V. Masson. 2000. Stable water isotopes in atmospheric general circulation models. Hydrol. Process., 14, 1385-1406.

Ichiyanagi, K., A. Numaguti and K. Kato. 2002. Interannual variation of stable isotopes in Antarctic precipitation in response to El Niño-Southern Oscillation. Geophys. Res. Lett., 29(1), 1001. (10.1029/2000GL012815.)

Johnsen, S.J., W. Dansgaard and J.W.C. White. 1989. The origin of Arctic precipitation under present and glacial conditions. Tellus, 41B $(4), 452-468$.

Jouzel, J., R.D. Koster, R.J. Suozzo, G.L. Russell, J.W.C. White and W.S. Broecker. 1991. Simulations of $\mathrm{HDO}$ and $\mathrm{H}_{2} \mathrm{O}-18$ atmospheric cycles using NASA GISS General Circulation Model: sensitivity experiments for present-day conditions. J. Geophys. Res., 96, 7495-7507.

Jouzel, J., R.D. Koster, R.J. Suozzo and G.L. Russell. 1994. Stable water isotope behavior during the last glacial maximum: a general circulation model analysis. J. Geophys. Res., 99(D12), 25,791-25,802.

Kato, K. 1978. Factors controlling oxygen isotopic composition of fallen snow in Antarctica. Nature, 272(5648), 46-48.

Kreutz, K.J., P.A. Mayewski, I.I. Pittalwala, L.D. Meeker, M.S. Twickler and S.I. Whitlow. 2000. Sea level pressure variability in the Amundsen Sea region inferred from a West Antarctic glaciochemical record. J. Geophys. Res., 105(D3), 4047-4059.

Lomb, N.R. 1976. Least-squares frequency analysis of unequally spaced data. Astrophys. Space Sci., 39, 447-462.

Merlivat, L. and J. Jouzel. 1979. Global climatic interpretation of the deuterium-oxygen 18 relationship for precipitation. J. Geophys. Res., 84(C8), 5,029-5,033.

Meyerson, E.A., P.A. Mayewski, K.J. Kreutz, L.D. Meeker, S.I. Whitlow and M.S. Twickler. 2002. The polar expression of ENSO and sea-ice variability as recorded in a South Pole ice core. Ann. Glaciol., 35, 430-436.

Morgenstern, U. and C.B. Taylor. In press. Low-level tritium measurement using electrolytic enrichment and LSC. In Proceedings of the International Symposium on Quality Assurance for Analytical Methods in Isotope Hydrology, 25-27 August 2004, Vienna, Austria. Vienna, International Atomic Energy Agency.
Parker, D.E. 1983. Documentation of a Southern Oscillation index. Meteorol. Mag. 112, 184-188.

Percival, D.B. and A.T. Walden. 1993. Spectral analysis for physical applications: multitaper and conventional univariate techniques. Cambridge, etc., Cambridge University Press.

Pourchet, M. and F. Pinglot. 1979. Determination of the stratospheric residence time from the total $\beta$ activity of Antarctic and Greenland snows. Geophys. Res. Lett., 6(5), 365-367.

Ribera, P. and M.E. Mann. 2003. ENSO related variability in the Southern Hemisphere, 1948-2000. Geophys. Res. Lett., 30(1), 1006. (10.1029/2002GL015818.)

Rockey, C.C. and D.A. Braten. 1995. Characterization of polar cyclonic activity and relationship to observed snowfall events at McMurdo Station, Antarctica. In Proceedings of the Fourth Conference on Polar Meteorology and Oceanography, Dallas, TX, 15-20 January 1995. Boston, MA, American Meteorological Society, 224-245.

Savage, M.L., C.R. Stearns and G.A. Weidner. 1988. The Southern Oscillation signal in Antarctica. In Second Conference on Polar Meteorology and Oceanography, 29-31 March 1988, Madison, Wisconsin. Boston, MA, American Meteorological Society, 141144.

Scargle, J.D. 1982. Studies in astronomical time series analysis. II. Statistical aspects of spectral analysis of unevenly spaced data. Astrophys. J., 263(2), 835-853.

Scargle, J.D. 1989. Studies in astronomical time series analysis. III. Fourier transforms, autocorrelation functions, and cross-correlation functions of unevenly spaced data. Astrophys. J., 343(2), 874-887.

Schulz, M. and K. Stattegger. 1997. Spectrum: spectral analysis of unevenly spaced paleoclimatic time series. Comput. Geosci., 23(9), 929-945.

Siegel, A.F. 1980. Testing for periodicity in a time series. J. Amer. Stat. Assoc., 75, 345-348.

Simmonds, I. and K. Keay. 2000. Mean Southern Hemisphere extratropical cyclone behaviour in the 40-year NCEP-NCAR reanalysis. J. Climate, 13(5), 873-885.

Smith, S.R. and C.R. Stearns. 1993. Antarctic pressure and temperature anomalies surrounding the minimum in the Southern Oscillation index. J. Geophys. Res., 98(D7), 13,071-13,083.

Taylor, C.B. 1971. Influence of 1968 thermonuclear tests on tritium fallout in the Southern Hemisphere. Earth Planet. Sci. Lett., 10, 196-198.

Turner, J. 2004. The El Niño-Southern Oscillation and Antarctica. Int. J. Climatol., 24, 1-31.

Vimeux, F., K.M. Cuffey and J. Jouzel. 2002. New insights into Southern Hemisphere temperature changes from Vostok ice cores using deuterium excess correction. Earth Planet. Sci. Lett., 203(4), 829-843.

Welch, P.D. 1967. The use of fast Fourier transform for the estimation of power spectra: a method based on time averaging over short, modified periodograms. IEEE Trans. Audio Electroacoust., 15(2), 70-73. 